\title{
Dime cómo te vistes y te diré quién eres. Un estudio del material arqueológico de la iglesia de La Candelaria de Bogotá
}

\author{
David Cohen Daza
}

\section{Introducción}

El presente trabajo surge como resultado de un proyecto de investigación formulado dentro de la línea denominada "Cultura material y sociedad" del grupo "Herencia Cultural” de la Fundación Erigaie y cofinanciado por el Departamento Administrativo de Ciencia, Tecnología e Innovación de Colombia (Colciencias). El proyecto, que metodológicamente comenzó con una catalogación e inventario del material arqueológico recuperado en la excavación realizada por los arqueólogos Monika Therrien y Javier Rivera en 2004 en la iglesia de La Candelaria, condujo al estudio de diferentes objetos empleando técnicas arqueométricas y de análisis de materiales, que fueron llevadas a cabo por el Laboratorio de Ciencias de la Conservación, a cargo del ingeniero químico Mario Omar Fernández, y el Centro de Microscopía Electrónica de Barrido de la Universidad de los Andes de Bogotá.

La prospección arqueológica de la iglesia en 2004, surgió como una investigación enfocada a mejorar el conocimiento de las prácticas funerarias coloniales, aprovechando los trabajos de conservación-restauración que se estaban llevando a cabo en el templo para ese momento.

El material cultural excavado está directamente relacionado, en su mayoria, con 30 de los 91 cuerpos hallados en diferentes enterramientos, ubicados hacia el costado oriental de la nave central del templo entre el presbiterio y el primer arco; este lugar, siguiendo la lógica propia de las inhumaciones dentro de las iglesias, resulta ser uno de los más privilegiados por su cercanía al altar mayor (y asimismo uno de los más costosos), por lo que las hipótesis de trabajo suponían que se trataba de individuos pertenecientes a las élites de la capital del Nuevo Reino de Granada.

Estos entierros son posteriores a 1703 (año en el que se termina de construir el templo) y llegan hasta comienzos del siglo XX; de acuerdo con lo señalado por los investigadores que realizaron las excavaciones, a pesar que la legislación colombiana prohíbe desde 1827 en beneficio de la higiene el enterramiento de cadáveres en las iglesias, aparecieron evidencias (como una lápida) que datan de 1916, además del libro de cuentas que en 1937 confirma “[...] que para este momento aún se alquilaban nichos mortuorios para el descanso de los difuntos” (Rivera y Therrien, 2004, p. 28).

\footnotetext{
* Cómo citar este artículo: Cohen, D. (2014). Dime cómo te vistes y te diré quién eres. Un estudio del material arqueológico de la iglesia de La Candelaria de Bogotá. Apuntes, 27(2), 26-41. http://dx.doi.org/10.11144/Javeriana.apc27-2.dcvd
} 

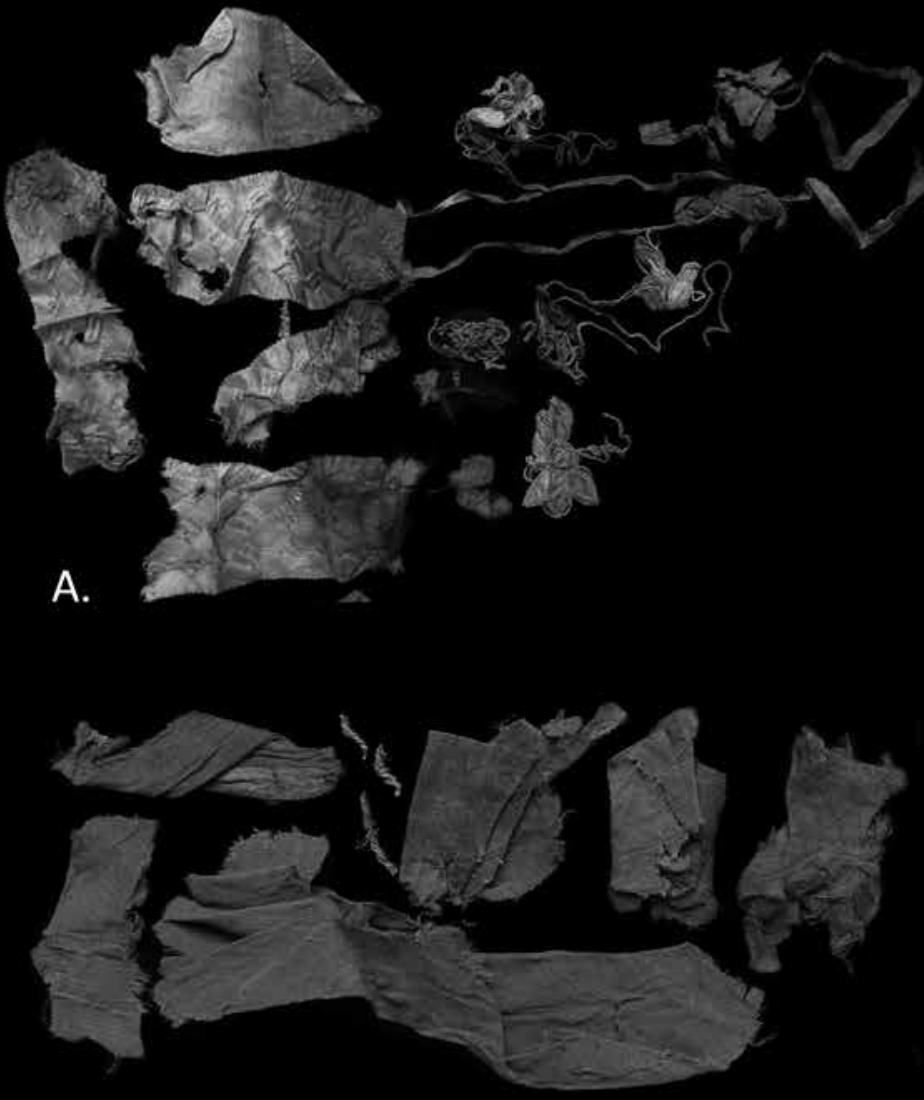

B.

C.
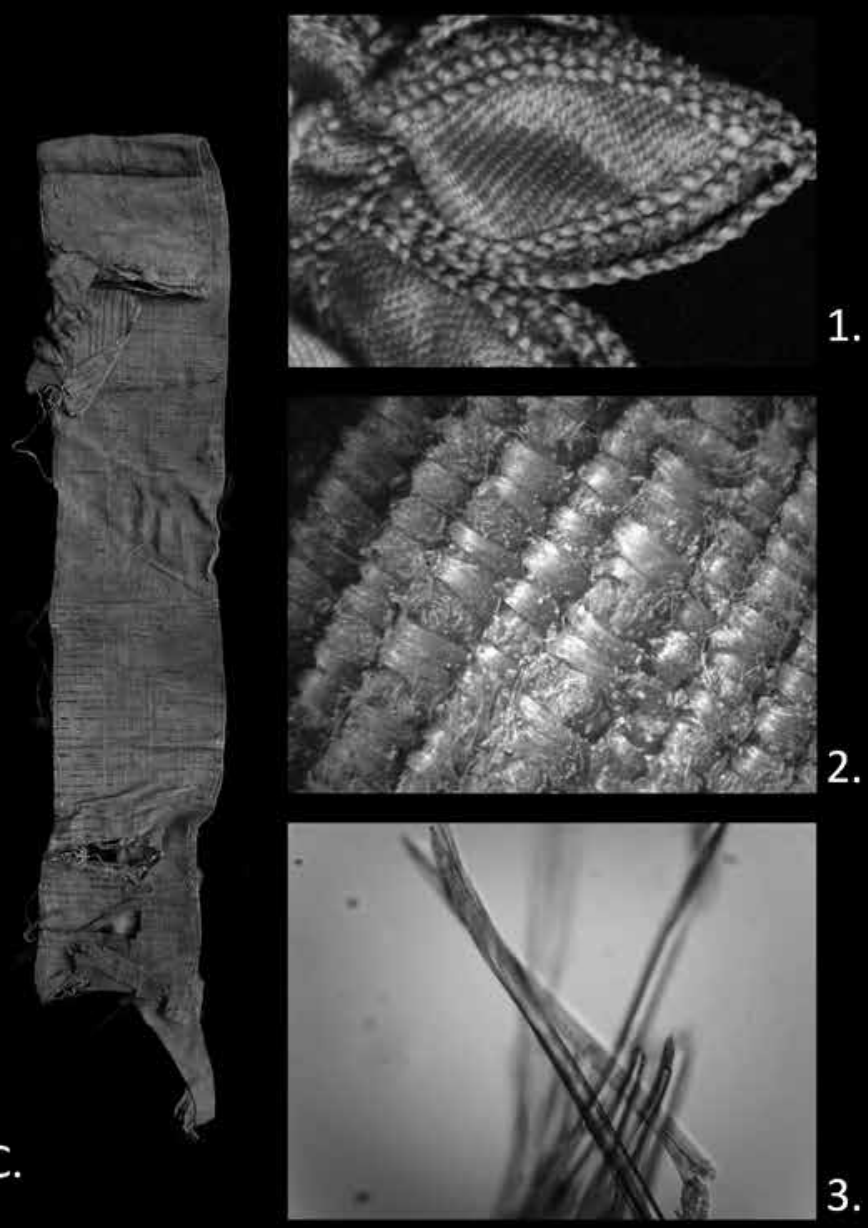

Diversidad de textiles hallados las excavaciones de los enterramientos en la iglesia de La Candelaria, Bogotá.

Fuente:

Fotografías y macrofotografías tomadas por David Cohen y Mario Omar Fernández. Laboratorio de análisis científicos para la conservación, 2013. 


\section{Dime cómo te vistes y te diré quién eres. Un estudio del material arqueológico de la iglesia de La Candelaria de Bogotá}

Tell me How you Dress and I Will Tell you Who you Are. A Study of the Archaeological Material from "La Candelaria" Church in Bogotá

Diga-me como você se veste e te direi quem você é. Um estudo do material arqueológico da igreja de "La Candelaria" em Bogotá

David Cohen Daza

David.cohen.daza@gmail.com

Conservador -restaurador de bienes muebles y magíster en Patrimonio Cultural y Territorio. Se ha desempeñado como docente en varias universidades y actualmente trabaja como investigador de la Fundación Erigaie en temas de conservación, arqueometría y arqueología histórica.

Resumen

La importancia que tienen los elementos de vestido y los objetos personales en los estudios de cultura material es bien conocida, aunque en el contexto colonial de la Nueva Granada existen muy pocas evidencias arqueológicas o investigaciones que permitan comprender mejor cómo eran los procesos y prácticas individuales y colectivas en el vestirse y, en particular, en el vestirse para la muerte. Más allá de las imágenes ampliamente difundidas y fuertemente estereotipadas de las clases sociales y raciales del período colonial y la manera como se supone se debían vestir unas y otras personas, este trabajo de investigación pretende generar una reflexión acerca de la construcción de estas categorías de análisis, que limitan la interpretación en términos de la producción, consumo, comercio y uso de diferentes bienes relacionados con el vestuario. Se presentan los resultados del estudio, elaborado a partir de los análisis de laboratorio de las evidencias arqueológicas recuperadas en 2004 durante las excavaciones de los enterramientos en la iglesia de La Candelaria que incluyen textiles, elementos religiosos, zapatos, adornos y otra serie de objetos personales pertenecientes al periodo entre el siglo XVII y comienzos del XX, en Santafé de Bogotá.

Palabras clave: arqueología histórica; estudios de cultura material; arqueometría, patrimonio arqueológico; textiles arqueológicos

Abstract

The importance of clothes and the act of dressing is well known for the material culture studies. However, in the colonial context of the Reign of Nueva Granada, there are a very few archaeological evidences, or researches of this kind, looking for a better understanding of the individual or collective practices of dressing, and particularly those practices related to the burial of the bodies. Despite the widespread and strongly stereotyped images of social classes during the colony, and the apparently obvious ways in which those classes were supposed to dress, the current research presents theoretical considerations about the construction of these categories, and their troubles in terms of the interpretation of production, consumption, trade and use of different cloths and goods. The results are based on the laboratory analysis of the archaeological evidences recovered back in 2004, during the excavations of the burials in "La Candelaria" church. The material includes garments, religious ornaments, shoes, adornments and other elite personal items from $18^{\text {th }}$ century to early $20^{\text {th }}$ century in Santafe de Bogotá.

Keywords: historical archaeology; material culture studies; archaeometry; archaeological heritage; archaeological textiles

Resumo

Apesar da importância que têm o vestido e os objetos pessoais nos estudos de cultura material, existem poucas evidências arqueológicas e pesquisas sobre estes temas para o contexto colonial da Nova Granada que permitam compreender melhor os processos e práticas individuais e coletivas em torno do fato de vestir-se; e em particular, de vestir-se para a morte. Além das imagens amplamente difundidas e fortemente estereotipadas das classes sociais e raciais na Colônia, assim como também dos jeitos em que as diferentes pessoas supostamente tinham que sevestir, esta pesquisa pretende fazer uma reflexão teórica sobre a construção destas categorias e suas limitações para interpretar a produção, o consumo, o intercâmbio e o uso de diferentes tipos de roupas e bens. As conclusões

Artículo de investigación

Recepción: 24 de febrero de 2014

Aceptación: 18 de mayo de 2014

Disponible en línea: 10 de diciembre de 2015 do estudo fundamentam-se nas análises de laboratório das evidências arqueológicas recuperadas em 2004 durante as escavações dos enterramentos na igreja "La Candelaria". Tais evidências incluem têxteis, ornamentos religiosos, calçados, adornos e outros objetos pessoais que pertenceram às elites entre o século XVIII e começos do século XX em Santafé de Bogotá.

Palavras-chave: arqueologia histórica; estudios de cultura material; arqueometria; património arqueológico; têxteis arqueológicos

doi:10.11144/Javeriana.apc27-2.dcvd 
Figura 3: De los objetos personales encontrados en las excavaciones de la iglesia, vale la pena resaltar los artículos religiosos como escapularios en tela (A) o los crucifijos de diferentes tamaños y materiales (B y C). Es posible pensar que este tipo de objetos, como demostraciones de

fe, acompañarán a los difuntos en un momento incierto de la existencia, como es la muerte, dentro de la concepción católica del mundo. Fuente: Fotografías y macrofotografías tomadas por David Cohen. Fundación Erigaie, 2013

1. Todas las traducciones son realizadas por el autor.

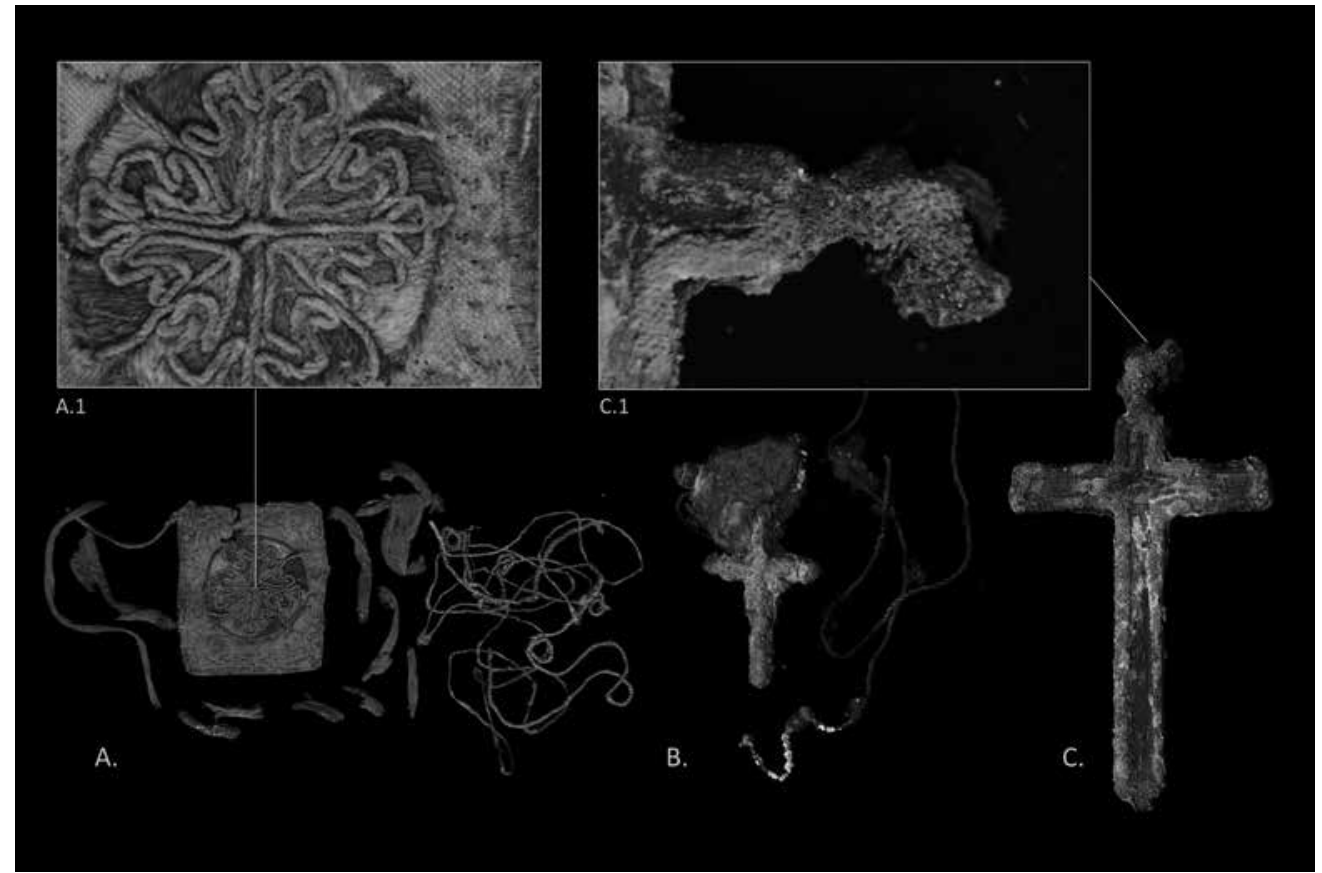

Quizás en la actualidad, los seres humanos hayamos naturalizado tanto ciertos aspectos del consumo, el comercio y el uso del vestuario y la moda, que ni siquiera pensamos en cómo se producen y se reproducen estas prácticas, y mucho menos logramos imaginar lo que significaba comprar un abrigo en tela o un par de zapatos en una ciudad como la Santafé de Bogotá del siglo XVIl. Esta es precisamente la intención principal de este artículo: hacer una invitación a pensar o imaginar el pasado de Bogotá y sus habitantes, a partir del acercamiento a la materialidad de unos objetos que, recuperados del registro arqueológico, han logrado sobrevivir y llegar hasta nosotros.

\section{Ser y parecer. El estudio del vestuario} como fuente de investigación

Durante los últimos años el desarrollo de la arqueología histórica ha ido tomando distancia de la arqueología "tradicional" no solo en términos de las diferencias con respecto a los métodos que se emplean para la excavación y posterior documentación del registro arqueológico, sino más bien, en términos de cómo analizar las evidencias obtenidas e interpretarlas; sin entrar en generalizaciones, que desde luego siempre son absurdas, la arqueología tradicional se ha preocupado de las grandes "civilizaciones" y de la comprensión de las sociedades, dejando de lado las historias de vida propias de personas individuales, especialmente cuando se trata de perso- nas comunes y corrientes; de ahí que los restos de objetos personales que se encuentran suelen ser interpretados a la luz de grandes conjuntos de datos, sin que necesariamente se planteen preguntas de investigación que estén dirigidas al conocimiento de la vida cotidiana de las personas; esta es una de las grandes diferencias entre ambos tipos de investigación arqueológica debido a que, en buena medida: "La arqueología histórica cada vez más, se ha dado cuenta del potencial interpretativo de todas las formas de hallazgos pequeños excavados, para la comprensión de la construcción de la identidad personal" (Cochran y Beaudry, 2006, p. 199)'.

Más allá de las consideraciones teóricas que tiene el concepto "poroso", por decir lo menos, de identidad personal, lo que resulta claro es el papel que juegan el vestuario y los adornos en la comprensión de los modos de vida y de las maneras particulares en las que se producian y se consumían bienes asociados al atuendo en el contexto de una sociedad colonial. "Más allá que simplemente cubrir el cuerpo, la presentación del cuerpo a través del vestido y el adorno, ofrece una de las manifestaciones más visuales de la identidad propia y el ser" (Di Paolo y Loren, 2006, p. 263).

Esta idea de la configuración del ser y de su imagen, hace parte de lo que se denomina estilo de vida, un concepto que resulta de gran utilidad como categoría de análisis del registro arqueológico, dado que, "[...] metodológicamente corres- 
pondería a una serie de expresiones de la vida diaria compartidas por un segmento de la población, que adquiere sentido en confrontación al de otros pero no necesariamente a la totalidad de la población" (Therrien, Lobo y Gaitan, 2003, p. 13).

De esa manera, en una sociedad estamentaria como la colonial, el análisis de los objetos personales e imagen propia, no solo brindaba información acerca de las condiciones económicas y sociales del individuo, tal y como sigue sucediendo hoy, sino que además, "En un mundo occidental dominado por las potencias coloniales europeas, los cortes, adornos, telas y colores proferidos por uno y otro sector de la sociedad, dejaban muy en claro que las tendencias del vestir estaban cargadas de información sobre la ubicación y las características del centro geográfico, político y económico del mundo occidental del momento" (Therrien et al., 2003, p. 7).

En ese sentido, ser español o "criollo" en la Nueva Granada simplemente no bastaba si no se lucía como tal. Esta diferenciación, basada en una agresiva idea de raza como concepto social, que perduró a lo largo de toda la colonia y buena parte del periodo republicano en Colombia, implicó el uso de unos atuendos "propios" de cada estamento, y también un juego en el que ocurría una transgresión de esas supuestas formas de ser.

Pensar el tema de las identidades como compartimientos aislados, sin entender las libertades y complejidades que se producían, ha dado como resultado la formación de estereotipos históricos, sustentados además en los múltiples grabados e imágenes que en Colombia han dejado, por ejemplo, los cuadros de la Comisión Corográfica, las acuarelas de viajeros como Roulin o Mark, o los trabajos de grandes artistas como Ramón Torres Méndez.

Llamar la atención sobre este aspecto no le resta valor a estos retratos de costumbres como fuentes de investigación, sino que, por el contrario, resalta la importancia de contrastarlas con los vestigios arqueológicos como una forma de enriquecer su interpretación, en tanto que las personas podían vestirse de una u otra manera, a pesar de los estamentos y las reglamentaciones asociadas a la imagen personal. En ese sentido, es posible hallar en un mismo contexto mezclas de bienes y materiales correspondientes a tradiciones distintas; tal y como lo señalan Di Paolo y Loren, "Los hallazgos pequeños relacionados con el acto de vestirse, pueden brindar información acerca del proceso de "convertirse en alguien" durante el periodo colonial, especialmente cuando combinaciones de hallazgos "nativo americanos" y "europeos" aparentemente dispares, sugieren que la gente en las colonias vestía de maneras únicas" (2006, p. 263).

Es precisamente en este tipo de casos en los que metodológicamente resulta de mayor utilidad la idea de estilo de vida; no se trata de negar categorías como "español”, “criollo”, “indio" o "mestizo", bajo las cuales se han analizado las relaciones sociales, culturales y económicas durante la colonia; se trata de complejizar su entendimiento a través de la comprensión de las dinámicas propias de la cotidianidad, que en la práctica ocurrian, que han dejado una huella visible en el registro arqueológico y que permiten, mediante el análisis de la indumentaria, dar profundidad al hecho de pensar cómo era la vida en la colonia, qué evidencias nos quedan de esa vida, y cómo se comportaban y se relacionaban esas personas aparentemente pertenecientes a un determinado "tipo"; en otras palabras:

Se trata pues de la representación en el vestir de diversas prácticas cotidianas que muestran, cómo aquellas rígidas categorizaciones de lo blanco-dominante-rico, indígena-dominado-pobre, son reemplazadas por un panorama mucho más complejo y dinámico que visto en conjunto finalmente genera estilos de vida alternativos (Therrien et al., 2003, p. 55).

Ser español en la Nueva Granada no necesariamente significaba ser rico, tal y como lo sugiere el estudio de los testamentos coloniales (Therrien et al., 2003, p. 55), como tampoco se puede suponer que ser indio implicaba una pobreza extrema, o incluso el hecho de que unos y otros, al igual que aquellos "mestizos" que se encontraban en el medio del complicado diapasón racial-social, no utilizarán objetos e indumentarias de otros grupos, o intentarán parecerse a las élites dominantes, ya sea de América o de los centros europeos que en diferentes momentos marcaron la pauta de la moda.

El proceso de "parecerse a" o de "convertirse en" no solo implica tener los medios materiales para adquirir una serie de productos de vestuario e indumentaria, sino que sugiere dotar de significado los objetos que se usan (Di Paolo y Loren, 
2006, p. 264) y, sobre todo, poder tener acceso a esos bienes en un contexto comercial limitado por los altos costos derivados del transporte y la importación.

$Y$ es que, con respecto al estilo de vida y a la moda, no puede simplemente equipararse lo que ocurría en las colonias americanas con lo que estaba sucediendo en Europa, donde, en efecto, la demanda de diversos sectores sociales de prendas reservadas para la élite, condujo a varios intentos por reglamentar el vestuario en diferentes cortes como la de Carlos V en España, Luis XIII en Francia o Enrique IV en Inglaterra, a partir de decretos encaminados a la prohibición en el uso de bordados o sedas (Boucher y Deslandres, 1987, p. 252).

Estas repetidas prohibiciones resultaron inútiles en la práctica, debido a los intereses comerciales que generó el consumo de estos bienes y que alcanzaron en el siglo XVIIl su punto culminante debido a dos hechos diferentes: por un lado, la apertura de los puertos españoles al libre comercio en 1778 (Boucher y Deslandres, 1987, p. 293) y por otro, la revolución francesa de 1789. Pero estos cambios en las pautas europeas de consumo, no pueden equipararse, de forma automática, con lo que estaba ocurriendo en el nuevo mundo, debido a que:

La tendencia a la nivelación en todos los estamentos sociales que se abrió paso con fuerza irresistible a partir de la revolución francesa [...] en la época colonial sufrió mu- chas restricciones, y hasta el final de ella se mantuvo en América la discriminación. Esto tuvo una consecuencia importante. Los modelos exclusivos importados, eran privilegio de las clases adineradas [...], mientras que la gente de menos valer compraba telas importadas y confeccionaba sus propios vestidos. Por eso nunca la moda europea campeó exclusiva en América, sino que sufrió los retoques del gusto personal de indianas y criollas, sin hablar del desfase cronológico, que hacía lenta e incompleta la difusión de las modas (Patiño, 1992, p. 123).

Mientras en Europa el consumo de ciertos bienes de lujo trató de mantenerse relativamente limitado a partir de las diferentes prohibiciones y reglamentaciones del vestir, en América, por el contrario, se estimula el comercio y el contrabando de materias primas para las confecciones locales, debido al elevado recaudo fiscal que este tipo de objetos tenían (Patiño, 1992 p. 173).

Las evidencias arqueológicas halladas en la iglesia de La Candelaria sustentan en buena medida esta afirmación, apoyando la idea de que el flujo de materias primas como hilos y telas importadas (elaboradas en seda por ejemplo), tenían una amplia difusión en Santafé de Bogotá, al menos, para las personas que podían pagar una inhumación dentro del templo; independientemente de si vestir al muerto con ropas de seda

la mayor parte corresponde a fibras de seda, empleadas para la fabricación de diferentes tipos de objetos como gorros de bebé (A), forros de abrigos (B) y cintas $o$ cinturones (C). Esta información es posible de obtener gracias a la identificación científica de las fibras realizada mediante la observación en diferentes aumentos como lupas (1) y microscopios (2 y 3).

Fuente:

Fotografías y macrofotografías tomadas por David Cohen. Fundación Erigaie, 2013. Microfotografía (3) tomada por Mario Omar Fernández.

Laboratorio de análisis científicos para la conservación, 2013

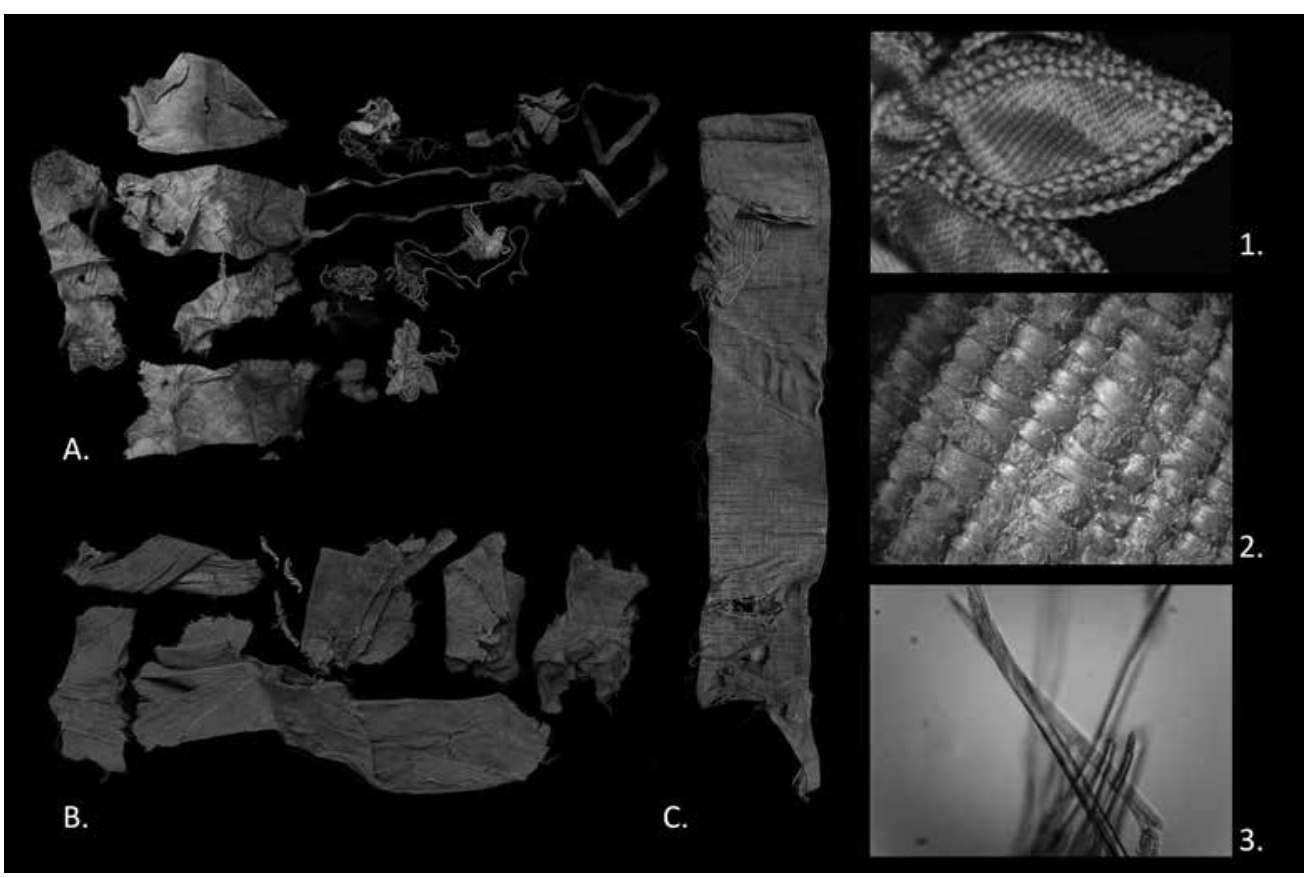


fue una costumbre asociada al ritual funerario (lo cual podría explicar su abundancia en el contexto arqueológico de La Candelaria), la presencia mayoritaria de este material foráneo en los ajuares encontrados implica, desde luego, poder tener acceso a ellos, no solo desde el punto de vista de los medios materiales para pagarlos, sino, más bien, de la oportunidad de poder adquirirlos y de tener una oferta que supliera la demanda.

Hilos de seda, de lana y de oro

Como ya se mencionó, la mayoría de los fragmentos textiles hallados presenta fibras de seda como parte de su composición. Pero más allá del material mismo y de las connotaciones comerciales, resulta fundamental observar las formas en las que aparece asociada la seda como materia prima de los productos, al igual que las tecnologías involucradas en la fabricación de estos tejidos, que dan cuenta, además, de los procesos de manufactura, de unos costos y formas de producción que sirven como indicadores del poder adquisitivo de sus propietarios, y también del momento en que fueron producidos; todo ello contribuye a la datación misma de los enterramientos.

Pese a que no fue posible recuperar prendas textiles completas, a excepción de un gorro en satín perteneciente a un individuo infantil, la seda aparece principalmente en telas delgadas y ligeras (como tafetanes y teletones) que pueden corresponder a piezas como camisas, o a forros interiores de prendas más gruesas.

Tampoco es posible establecer si las telas de seda fueron importadas directamente o si, por el contrario, la importación era solo de los hilos y la producción textil era realizada localmente; en cualquier caso, este tipo de telas contrasta enormemente en términos de las cantidades encontradas en las excavaciones, con el hallazgo minoritario de otras telas hechas con ese material, como el terciopelo, que claramente era importado. Del siglo XVIIl en España, por ejemplo, en el Archivo de Indias de Sevilla se encuentran preservados catálogos de venta de terciopelos, teniendo en cuenta además, que la región de Murcia era famosa por la producción de hilos seda y otras manufacturas, que generaron una fuerte competencia comercial con la producción inglesa de lana: "El principal competidor de la lana era la seda, proveída principalmente por Italia [...] y España. La seda de Murcia era generalmente

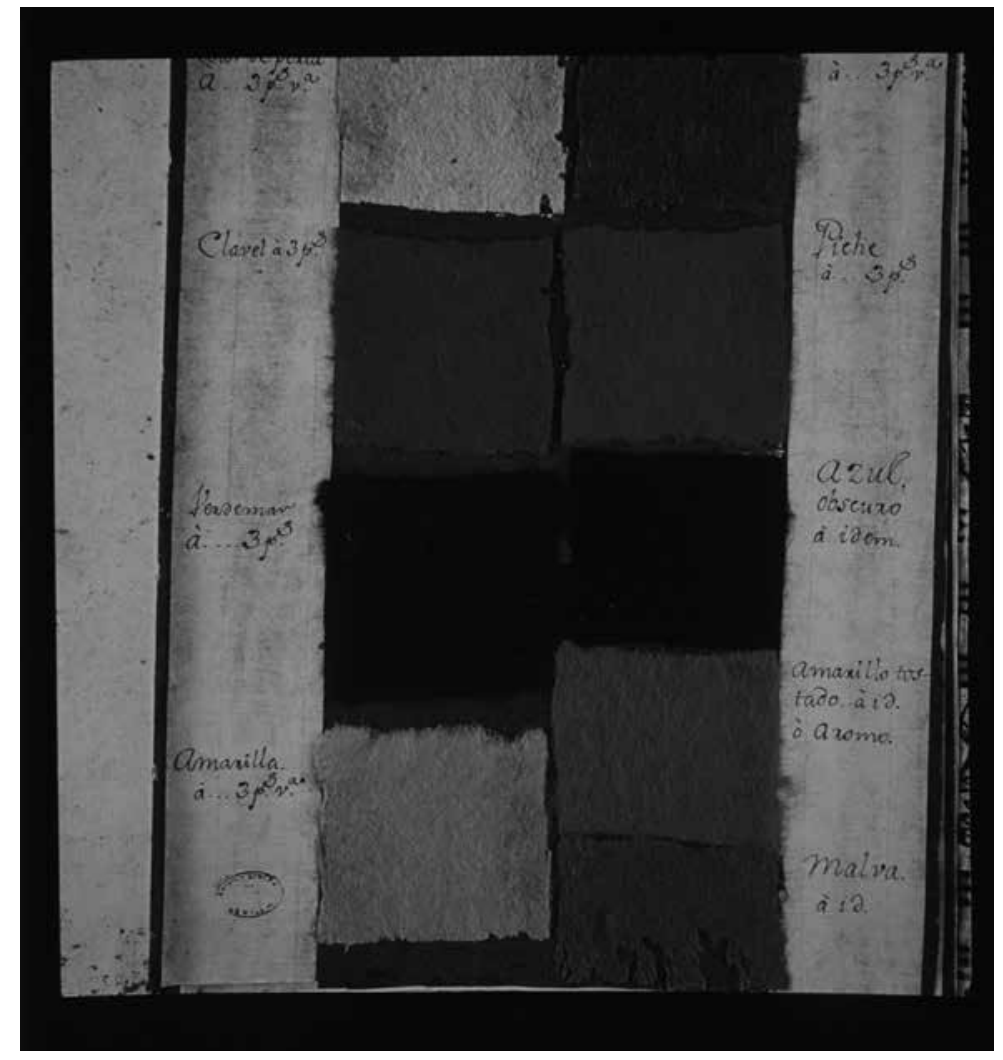

usada para encajes. Ciertos tipos de seda eran el material más ampliamente utilizado en los trajes de los ricos” (Boucher y Deslandres, 1987, p. 281).

Si de costos se trata, los precios más elevados corresponden a los hilos de seda dorados (asociados a cinco individuos enterrados en la iglesia) y que por los materiales y técnicas empleadas, parecen ser del siglo XIX. La producción de hilos de seda recubiertos de láminas planas de plata dorada o de oro para los bordados se realizaba en Europa desde la edad media, aparentemente empleando una tecnología procedente de la India (Symonds y Preece, 1928, p. 33). En efecto, las primeras regulaciones de toda Europa que se conocen para el gremio de bordadores, fueron aprobadas por el preboste de París Guillermo de Hangest en 1303, mencionando en dos de sus ítems el uso del oro y ordenando que "[...] quien haga bordados en oro, utilice seda para coser" (Staniland, 2000, p. 14).

Pero la técnica de fabricación de hilos metálicos con alma de seda que se observa en las evidencias encontradas en La Candelaria, muestra una evolución de sus orígenes medievales, hasta un proceso casi industrializado. Un buen indicador de esto radica en el grosor perfectamente homogéneo de las láminas de oro que se enrollan alrededor de la seda y que en la escala microscópica demuestran el empleo de laminadoras o de rodillos
Figura 5:

este muestrario de siglo XVIll conservado en el Archivo de Indias de Sevilla, se exhiben nueve diferentes colores de terciopelo con su respectivo costo, que en términos generales, por lo que puede verse, era de tres piezas por vara. Fuente:

Diapositiva tomada del Fondo de Textiles 14, No. 36, Archivo de Indias de Sevilla. 
Figura 6:

En estas microfotografías electrónicas de barrido de muestras tomadas de diferentes objetos excavados, se observa cómo la lámina plana de oro (en color blanco), va envolviendo el núcleo de hilos de seda. La apariencia de estos hilos coincide con la descripción de la técnica medieval que llevan a cabo Symonds y Preece.

Fuente:

Microscopías electrónicas de barrido tomadas en el Laboratorio MEB. Universidad de Los Andes, 2013.

Figura 7:

El espectro de dispersión (A) muestra una aleación de plata y oro como componente mayoritario del metal con que están hechas

las láminas (B) que envuelven hilos de seda.

Fuente:

Microscopía electrónica de barrido tomada en el Laboratorio MEB. Universidad de Los Andes, 2013.

Figura 8:

En esta microfotografía de un corte tangencial de uno de los hilos, se aprecia cómo el grosor de la lámina metálica alrededor del núcleo es perfectamente homogéneo, lo que en este caso implica un proceso si no industrializado, al menos si lo suficientemente estandarizado. A. Imagen tomada con luz reflejada a 20x. B. Imagen del corte tomada con luz transmitida (40x).

Fuente:

Microfotografías tomadas por Mario Omar Fernández.

Laboratorio de análisis científicos para la conservación, 2013
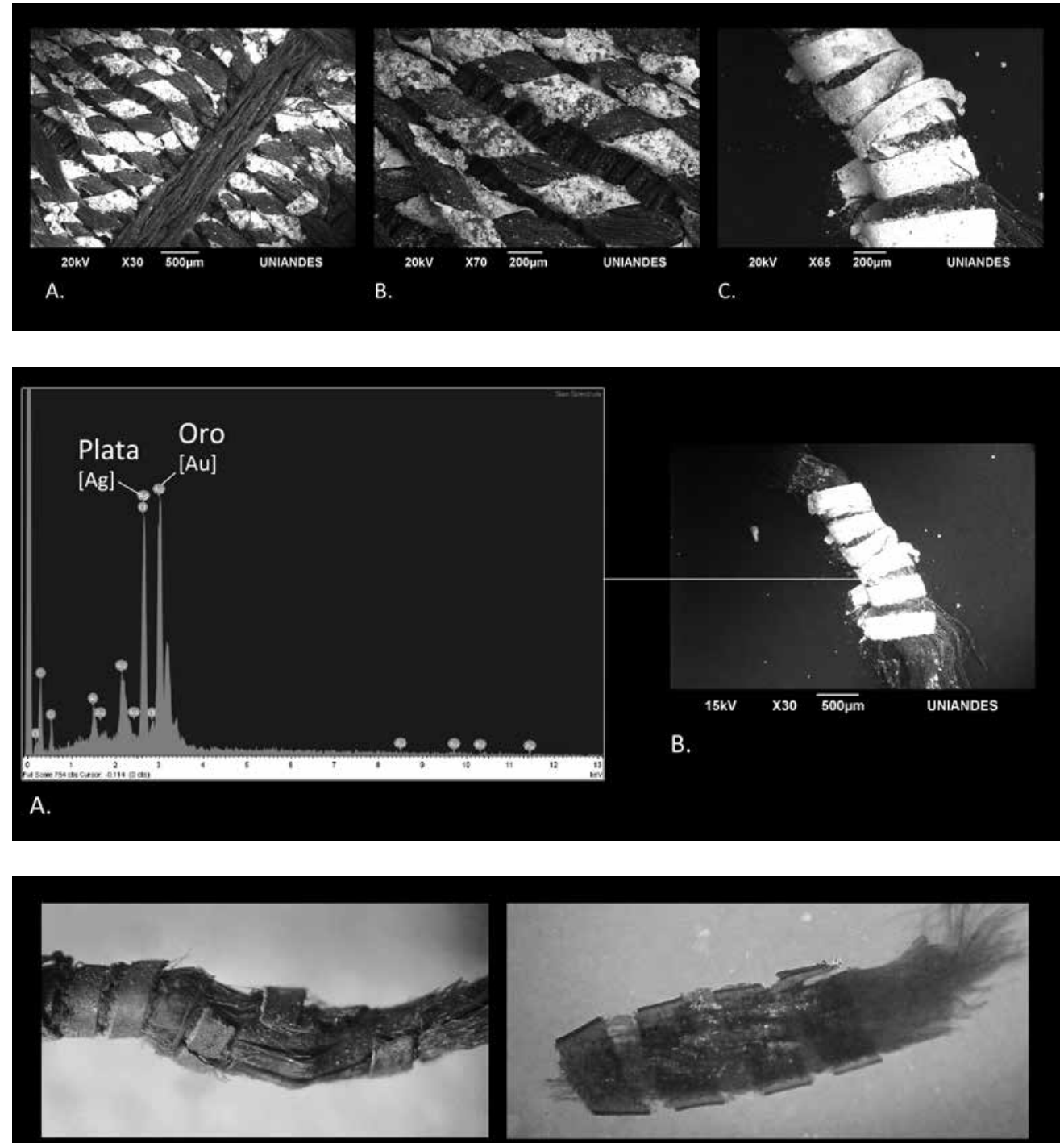

A.

que permitan la compresión regular de todas las partes del metal. Las técnicas de fabricación del siglo XIV, completamente manuales, mostraban irregularidades en el espesor de la lámina de oro, pues como lo mencionan Symonds y Preece (1928, p. 34): "Para aplanar este alambre, es golpeado con un martillo y su uniformidad y grosor, depende de la destreza del operador. El alambre aplanado, luego es enrollado alrededor del hilo de seda para darle flexibilidad y aumentar su tamaño”.

Además de lo complejo de la técnica, el elevado costo de estos hilos de bordado radicaba en la calidad de sus materiales pues, de acuerdo con el espectro de dispersión de rayos X (MEB-EDS) empleado para el análisis de las muestras, se trata de láminas de oro de alrededor de 20 micras de espesor (una micra equivale a la milésima parte de un milímetro: $1 \mu \mathrm{m}=0,001 \mathrm{~mm}$ ).
Este hecho quizás explique por qué el uso de estos hilos aparece relacionado con la fabricación de galones o cordones de seda tejidos (empleados como adornos adosados a los vestidos), forros para botones y como parte del bordado de piezas religiosas como los escapularios. Se encontraron, igualmente, hilos sueltos de este tipo, sin que sea posible establecer si pertenecían a un bordado, o si por el contrario eran utilizados como cadenas, para el adorno del cuerpo.

Paralelamente al uso de los hilos de seda y oro se encontró un fragmento de encaje de factura industrial, pero elaborado con láminas planas de bronce, casi como imitación del dorado hecho en oro, que, debido a los procesos de enteramiento, muestra abundantes productos de corrosión.

En relación con otros materiales, se identificaron (cuantitativamente en un segundo lugar) 


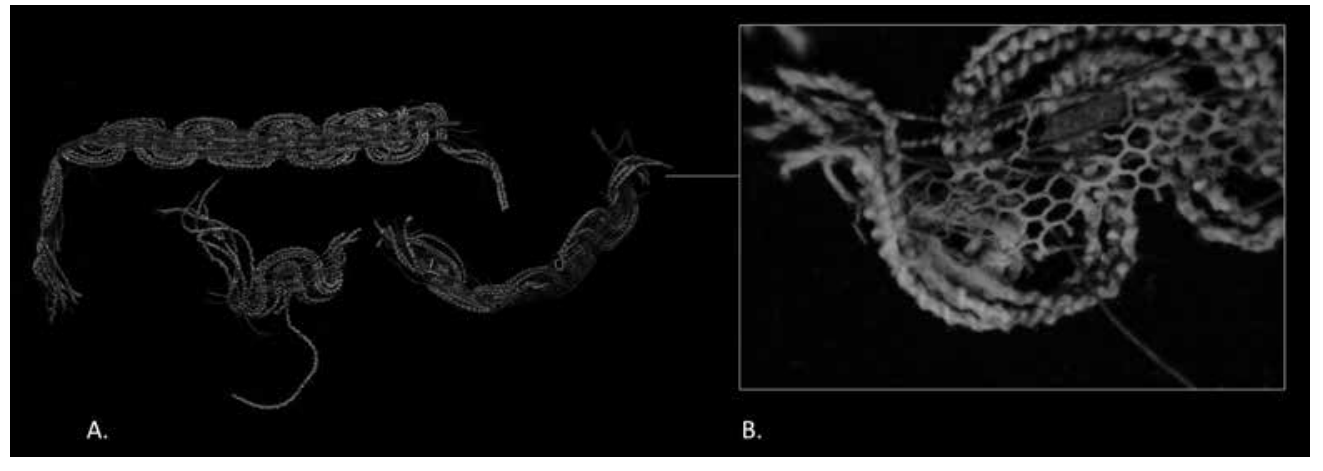

hilos de lana correspondientes a diferentes tipos de mantas, algunas de tejido grueso de baja densidad de hilos y otras de tejido muy fino (con un mayor número de hilos por centímetro cuadrado), que según las descripciones históricas, pueden corresponder al bayetón y a la ruana respectivamente, y que de acuerdo con Patiño “[...] parecen haberse derivado del poncho o ser una adaptación de él” (1992, p. 178).

Las marcadas diferencias y calidades encontradas entre los textiles de lana, no solo están dadas por la densidad de las telas, sino también por los colores empleados, que implican la tinción y el tratamiento de algunas de las fibras en con-

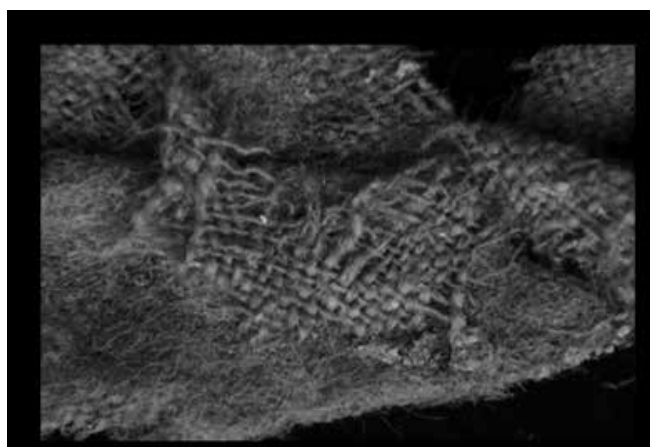

A.

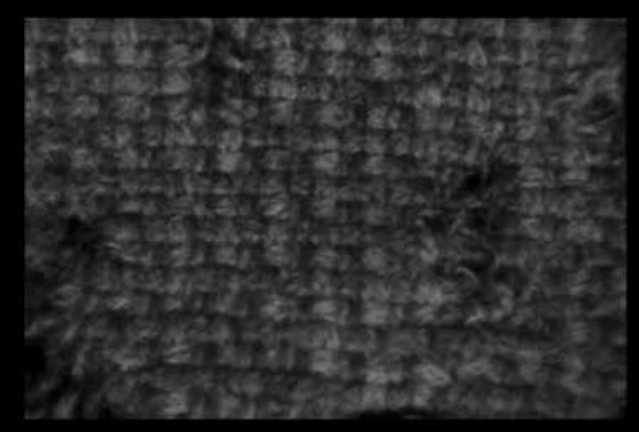

C.

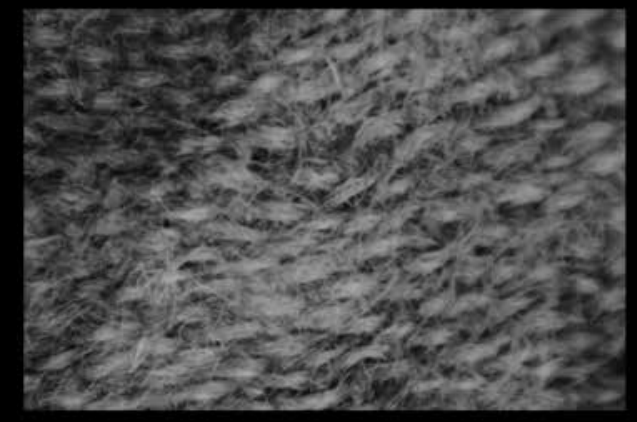

Figura 9:

Este encaje de factura industrial, tiene dentro de su tejido hilos

planos de bronce, que debido al enterramiento muestran la formación de diferentes productos de corrosión,

posiblemente carbonatos básicos de cobre.

Fuente:

Fotografías y macrofotografías tomadas por David Cohen. Fundación Erigaie, 2013.

Figura 10:
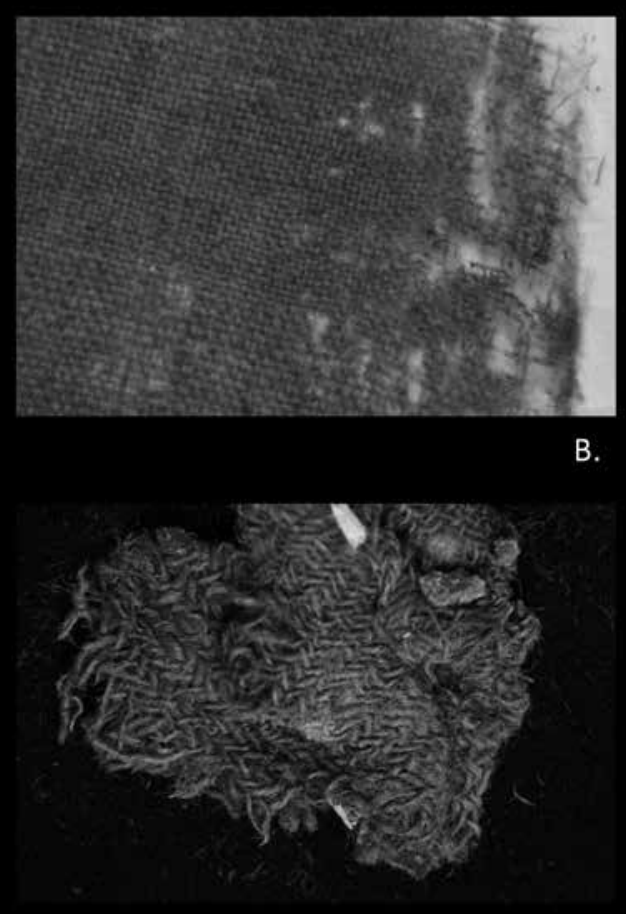

Ejemplos de tejidos elaborados con lana, encontrados en la iglesia de La Candelaria. Los tejidos más complejos y más densos forman espinas de pescado $y$ muestran combinaciones de colores con hilos amarillos, rojos y verdes (C, Dy F), mientras que otros tejidos muestran hilos de lana muy finos que componen telas delgadas (B) que contrastan con telas de trama más abierta $y$ de apariencia menos elaborada ( $A$ y E).

Fuente:

Fotografías y macrofotografías tomadas por David Cohen. Fundación Erigaie, 2013 
cordancia con el tipo textil: los fragmentos más densos que muestran tejidos más complejos, como "espinas de pescado" o "sargas", son igualmente aquellos que muestran combinaciones de colores.

A partir de los análisis realizados, no es posible identificar la procedencia de las materias primas a partir del tipo de animal (ovejas o camélidos, por ejemplo), pero la apariencia que muestran los fragmentos recuperados puede tener relación con la fabricación local o por lo menos americana.

Asociado a la idea del uso de materiales o productos locales, un hecho que llama poderosamente la atención en el análisis de los hallazgos de La Candelaria, es la ausencia de fibras de algodón. Sin descartar la posibilidad de que en efecto el algodón hiciera parte de los ajuares funerarios, pero que debido tanto a las condiciones de enterramiento como la acidez del suelo se haya degradado, resulta poco probable que no haya quedado ninguna evidencia del uso de este material.

Otra explicación para esta carencia radica en el hecho de que el algodón represente un tipo de tejido asociado a prendas de vestir propias de clases sociales más bajas y que, por lo tanto, deliberadamente no se haya utilizado en la preparación de los cuerpos enterrados en la iglesia, como una forma de mostrar prestigio y diferencia social; Patiño menciona que "El lienzo de algodón llamado tocuyo fue común en el período colonial [...] También de algodón era el fustán, usado para vestidos de esclavas, así como la tela denominada fula" (1992, p. 134). Asimismo, al realizar una revisión de los testamentos de ropas coloniales (compilados por Therrien et al., 2003, p. 56), no se observan ni para los blancos ni para los criollos, ropajes que hagan una referencia directa a telas fabricadas con algodón.

Haciendo un balance de los fragmentos textiles encontrados, resulta evidente la amplia predominancia de materiales o incluso de prendas y productos terminados de origen foráneo, frente al posible uso de materiales y tejidos de fabricación local.

\section{Zapatero a tus zapatos}

Entre ese juego de vestir a los muertos como demostración, casi idealizada, de la diferencia social y del prestigio que tuvieron en vida, la presencia del calzado al parecer cumplió un papel central. Patiño a este respecto menciona que "En la Nueva Granada, la diferencia social no se refería al vesti- do, sino al calzado" (1992, p. 161), afirmación que como se ha visto no es del todo correcta, aunque no por eso pierda su validez en tanto que el hecho de cubrirse los pies parece haber sido un indicador importante del estatus y de las aspiraciones de convertirse en parte de una élite.

En efecto, en una crónica que escribe Niles Blair, viajero inglés que pasó por Colombia hacia 1923 (citado por Sánchez, 2008, p. 29) describe un entierro que observa desde la ventana de su hotel, ubicado frente a la iglesia de San lgnacio de Bogotá:

[...] yo veía salir a la gente a raudales de la Iglesia [...] en los pies de la congregación había pocos zapatos, era claro por su magnitud numérica que el ritmo de las sandalias de cáñamo sobre el suelo aniquilarían el sueño [...]. La mejor parte de la congregación eran indios: los hombres con ponchos y las mujeres abrigándose con chales inadecuados, los hijos duplicando el traje de sus padres. Pero también había mujeres cuyas castas eran: cholos, mestizos o Españolas; mujeres cuyos pies estaban calzados con zapatos.

De la cita, además de la descripción de los trajes y las costumbres funerarias de comienzos del siglo $X X$, es necesario resaltar, en primera instancia, que el uso del calzado es empleado por Blair como una categoría de análisis demográfico, casi como punto de medida del grado de "civilización”, por otro lado, y más importante aún, el hecho de que portar zapatos no era exclusivo de “españoles" sino que al menos para el caso de las mujeres participantes del evento social narrado, otras "castas" distintas también usaban calzado.

Es posible que pese al interés por adquirir un par de zapatos "de material", es decir, con suela y empeine de cuero, la limitación en su uso esté directamente relacionada con el precio y no tanto con la dificultad de encontrarlos, puesto que estos bienes se fabricaban localmente.

De los tipos de calzado fabricados existian, además de los zapatos de cuero que cubrían todo el pie, las alpargatas y las guaireñas, que se caracterizaban por dejar el pie destapado y que en algunos casos mezclaban suelas planas de cuero con fibras de algodón, fique, cocuiza (tipo de cabuya) o esparto, con las que se fabricaba la parte superior, denominada "capellana". 

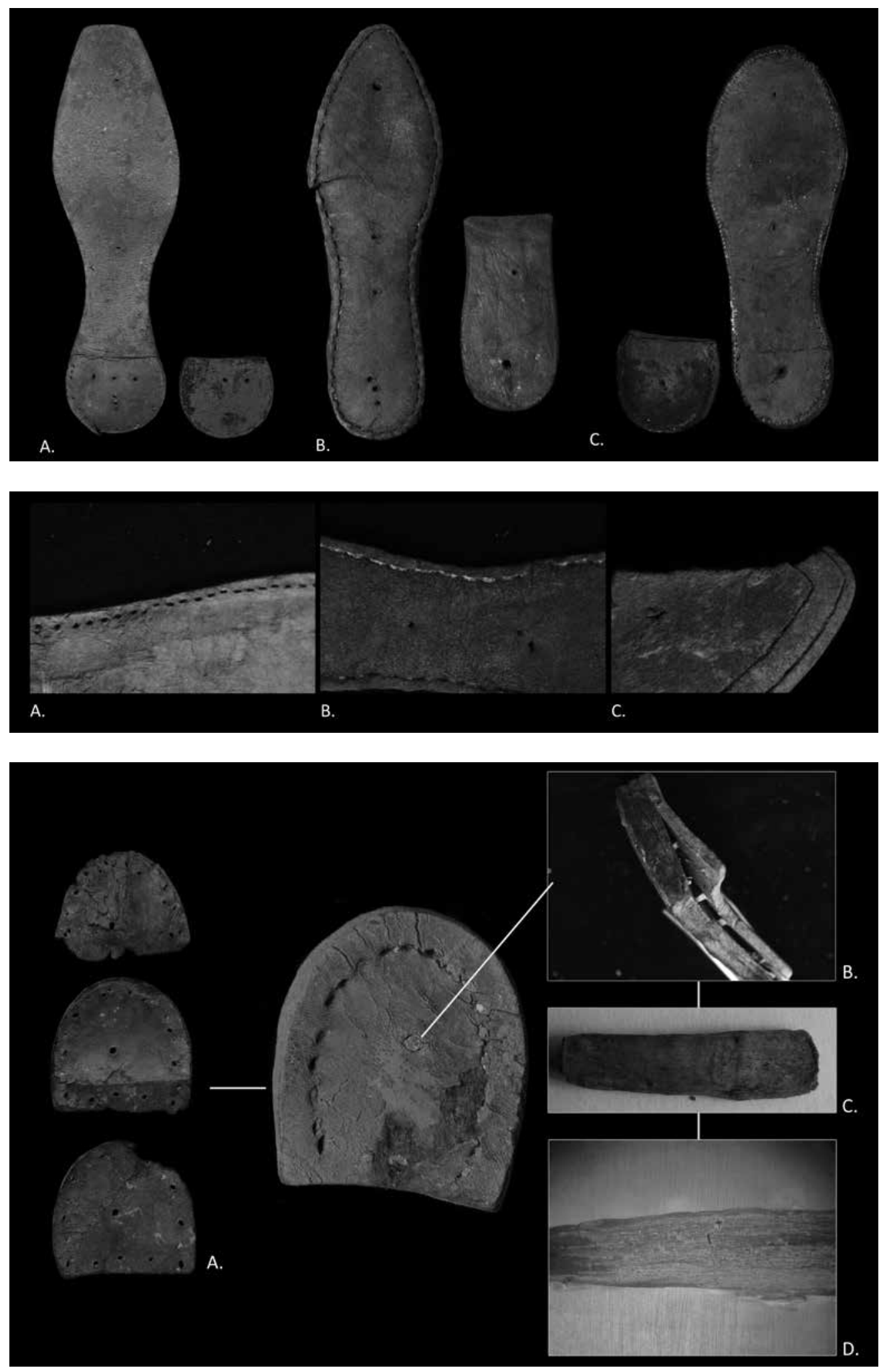

Al parecer, la producción local de este tipo de objetos y en particular de las alpargatas, alcanzó niveles considerables debido a la demanda interna, aunque en los ajuares funerarios de la iglesia, por razones obvias, no se encontraron alpargatas o fibras de este tipo; Francisco Jap. 163), menciona que para finales del siglo XIX (1898) se fabricaron en Colombia 70.000 pares de alpargatas.

En los entierros de La Candelaria, casi la mitad de los 64 fragmentos de zapato encontrados
Figura 11:

Diferentes suelas de zapatos encontradas como parte de los entierros. Se observan varios tipos de puntas y terminaciones que corresponden a cambios que se fueron dando en la moda del calzado a través del tiempo.

También existen diferencias reconocibles, de acuerdo con el tamaño, entre zapatos de hombre, mujer y niños.

Fuente:

Fotografías tomadas por David Cohen.

Fundación Erigaie, 2013

Figura 12:

Si se comparan los tipos de costura, es posible diferenciar aquellas realizadas manualmente ( $A$ y B) con aquellas que emplearon máquinas de coser (C) inventadas en la segunda mitad del siglo XIX.

Fuente:

Macrofotografías tomadas por David Cohen. Fundación Erigaie, 2013

Figura 13:

Las estaquillas es el nombre que reciben los clavos elaborados en caña o madera que permitían fijar el tacón a la suela. La importancia de emplear madera se debía al hecho de que con el agua esta se expande haciendo más duradero el ensamble entre ambos elementos. lzquierda, unión del tacón a la suela, derecha, microfotografía con el corte transversal de la madera (40x).

Fuente:

Fotografías y macrofotografías tomadas por David Cohen. Fundación Erigaie, 2013.

Microfotografía (3) tomada por Mario Omar Fernández. Laboratorio de análisis científicos para la conservación, 2013 
fueron recuperados a partir de una recolección superficial, mientras que el resto se asocia a 19 individuos, esto hizo posible diferenciar suelas, tacones y fragmentos de zapatos de mujer, hombres adultos y niños.

Asimismo, se identificaron diferentes tipos de terminaciones en las suelas, dado que algunas presentan punta redondeada, mientras que otras terminan en forma cuadrada o muy puntiaguda y alargada. En términos de la moda y la evolución del calzado, estas diferencias formales permiten de cierta manera establecer relaciones temporales. Se sabe, por ejemplo, que al menos en Europa, "Hacia 1652 la moda dio un giro hacia zapatos con punta [...] veinte años después, volvieron a ser de punta cuadrada y los tacones se hicieron más altos, probablemente debido a que Luis XIV quería aumentar su propia altura" (Boucher y Deslandres, 1987, p. 266).

Otros elementos analizados permiten establecer marcadores de datación más confiables, tal y como ocurre con la aparición de suelas armadas con costuras dobles regulares, propias de la máquina de coser. Patiño (1992, p. 199) menciona que "el invento de la máquina de coser inspiró la mecanización de la zapatería. En 1858, Lyman R. Blake patentó la primera máquina efectiva para esto [...] pero sólo después de 1871 se produjeron modelos de máquinas perfeccionadas. A mediados del siglo XIX se fabricaban en Sogamoso los zapatos de ese nombre para muchachos".

De igual forma, al analizar las suelas encontradas, se identificó el uso de materias primas americanas para la fabricación de las estaquillas, que es el nombre que reciben los clavos de madera que unen el tacón a la suela y que corresponden a madera de cedro macho, lo que corrobora que la importación de calzado, a diferencia de lo que ocurría con otras materias primas como los textiles de seda, no parece haber sido tan frecuente debido a la floreciente industria local.

\section{Prácticas funerarias}

Para llevar a cabo una interpretación acertada de los materiales culturales coloniales recuperados de la iglesia de La Candelaria, es necesario no perder de vista que los textiles, zapatos y adornos personales provienen de un contexto funerario, lo que hace necesario conocer o preguntarse cómo eran esas prácticas en la colonia y cómo han ido evolucionando hasta hoy, puesto que para los muertos no necesariamente se seguían las mismas reglas y lógicas del vestuario de los vivos.

La primera práctica funeraria que ha variado, evidentemente, es la prohibición de enterrar a los muertos dentro de las iglesias, que, como sucedió con muchas otras prohibiciones, tampoco resultó ser muy efectiva pues, de acuerdo con la información de los archivos parroquiales, hasta bien entrado el siglo $X X$ se seguían enterrando personas en la iglesia de La Candelaria, y también con la información de las evidencias arqueológicas, pues entre otras piezas se halló una cruz de color negro fabricada en baquelita, una especie de plástico sintetizado por primera vez en 1906 por el químico belga Leo Hendrik Baekeland.

La razón de este cambio en la manera y el lugar en el que se enterraban a los muertos, respondía, en parte, a problemas asociados con el concepto de higiene pública, aunque también por el hecho de que, a partir de la llustración, el cadáver deja de ser el estuche del alma (Martín y Díaz, 2000, p. 82).

$\mathrm{Al}$ ser el cuerpo despojado de su condición de contenedor de la inmortalidad, fue posible pensar en que la residencia del difunto se halle lejos de Dios (es decir, por fuera de las iglesias), algo que en la colonia resultaba imposible, dado que solo los suicidas eran enterrados en los extramuros (Contreras y Durand, 2009, p. 16).

Esta evolución en el pensamiento colonial y en el desarrollo de la idea, también ilustrada, de la necesidad de crear una morada para los muertos lejos de las ciudades, se sustenta en el cambio de las leyes coloniales en tanto que "la prohibición de esta práctica, por parte de la corona española, se reglamentó mediante Real Cédula el 3 de abril de 1787" (Martín y Díaz, 2000, p. 82). Estas disposiciones legales en algunos casos estuvieron sustentadas, al parecer, en la consolidación de la idea de salud pública que condujo a que los propios ciudadanos solicitaran la construcción de cementerios, tal como ocurrió en la ciudad de Lima (Contreras y Durand, 2009, p. 17).

Es posible que la entrada en vigencia de estas normas se haya demorado debido a la devoción popular, aunque seguramente existió cierta presión que en la práctica ejerció el clero para evitar que esto ocurriera; independientemente de las razones, lo cierto es que el caso de La Candelaria no es único y en varios países de América no fue sino hasta el siglo XIX que comenzó a ocurrir un cambio en la determinación de los lugares de inhumación. 
Por otro lado, el enterramiento en las iglesias durante los siglos XIX y XX está estrechamente ligado a la idea de élite, un hecho que al parecer sucedió en todo el continente pues, tal y como lo señala Eddy Armando Joaquin para el caso de Guatemala: "pese a la existencia de los cementerios [...] las familias de élite, continuaron inhumando a sus miembros en el interior de las iglesias, como se evidencia en La Merced (1853), Santo Domingo (1864), Los Remedios (1868), El Sagrario (1870) y Candelaria (1875)" (2008: 694).

Otro elemento dentro del ritual funerario que se fue trasformando a lo largo del período colonial en América es la mortaja, cuyo uso fue remplazado por la práctica de vestir a los muertos con la ropa que usaron en vida, un cambio que, desde luego, tiene mucho que ver con la concepción de la clase y la idea de mantenerla aún en el más allá.

En efecto, antes del siglo XVIII la mortaja era un símbolo de resurrección que emulaba el entierro sencillo de Cristo (Martín y Díaz, 2000, p. 82), lo que implicaba, para la gente del común, evitar el uso de la ropa como atuendo para los muertos; quizás las concepciones religiosas determinaron el tratamiento austero de los cadáveres, quizás simplemente resultaba más práctico y mucho más económico enterrar a los muertos con una tela simple, en especial si se tiene en cuenta que la ropa y los vestidos eran testados durante la colonia, y constituían el tercer renglón de posesiones más valiosas, después de los predios y el mobiliario.

Cualquiera que sea la razón del cambio, lo que resulta evidente es que la diferenciación social de los individuos, incluso después de la muerte, al parecer no fue un problema sino hasta el siglo XVIII: “[...] esta evidencia arqueológica, en combinación con el escaso uso de los ataúdes, indica una inversión limitada en el ritual funerario sin hacer mucho esfuerzo en mantener distinciones de clase post-mortem que indudablemente resultaban altamente importantes en vida" (Di Paolo y Loren, 2006, p. 262).

Esta nueva necesidad de mantener postmortem las diferencias, condujeron al uso de las prendas de vestir como parte de los ajuares funerarios y a la aparición paulatina del ataúd como un elemento que cobra fuerza dentro del ritual, posiblemente después del siglo XVIII de acuerdo a como lo señalan Martín y Díaz (2000, p. 82).

En las excavaciones de la iglesia de La Candelaria de Bogotá se recuperaron numerosos frag-

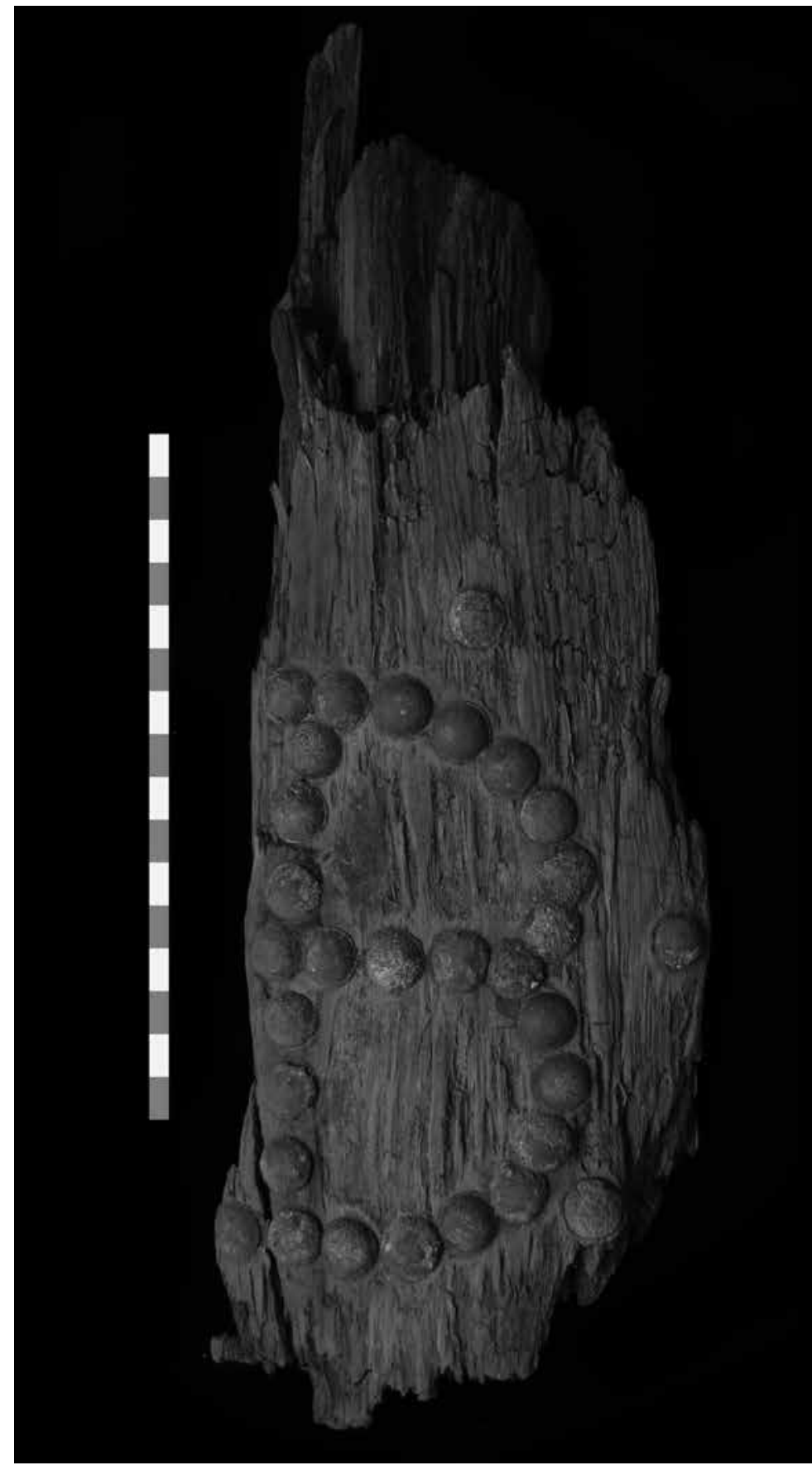

mentos de ataúd consistentes en clavos, tachuelas y maderas principalmente, además de una tapa completa. Estos fragmentos, sin embargo, solo se relacionan con 10 de los 91 individuos enterrados, lo cual corresponde a una cifra considerablemente baja, que apoya la idea de que en efecto, los ataúdes no fueron tan populares, incluso entre las personas consideradas como de élite.

La simplicidad en las formas y decoraciones de los ataúdes de la iglesia, compuesta fundamentalmente por el uso de tachuelas de bronce que forman líneas rectas o letras (posiblemente las
Figura 14:

Las decoraciones de los ataúdes con tachuelas eran muy simples $y$ consistian en crear hileras y líneas rectas, $o$ en formar letras, presumiblemente con las iniciales del muerto. En la imagen se observa la letra " $B$ ".

Fuente:

Fotografía tomada por David Cohen. Fundación Erigaie, 2013 
iniciales del nombre del difunto), contrastan con la riqueza de los tejidos y atuendos de los muertos. Esta diferencia hace pensar que el escaso uso del ataúd en los entierros de La Candelaria se debía más a la elección o el gusto, que a un problema de medios económicos o de limitaciones en el acceso a este tipo de objetos.

\section{Consideraciones finales}

No es fácil hacer el ejercicio de imaginar cómo era el estilo de vida de las personas enterradas en la iglesia de La Candelaria de Bogotá y, más aún, poder establecer a partir de la interpretación de los materiales culturales hallados, cuál fue el papel que tuvieron en vida y cómo manifestaron las diferencias sociales que son apreciables después de la muerte.

Es un hecho ampliamente discutido y documentado, como se ha visto en este trabajo, que las distinciones de raza y de clase se hacian visibles según el vestuario y la ornamentación del cuerpo $y$, en especial, con el uso de elementos y bienes fabricados en Europa, que solo determinadas personas podían usar para mostrarse diferentes a otras.

Sin embargo, también es un hecho, tal y como lo demuestra el análisis de la evidencia arqueológica, que la intención de diferenciarse implicaba en la práctica el uso de una amplia gama de objetos que no eran importados en su totalidad, sino que aparecen en combinación con telas y artículos de fabricación local en unas formas muy propias de adaptación de las tendencias y modas europeas.

Esto significa que el acceso a bienes que podrian considerarse de lujo, no solamente se relaciona con tener los medios económicos para adquirirlos, sino, más bien, con seleccionar qué objetos ponerse o no, para configurar la imagen personal.

De esa forma, es posible explicar que no se hayan encontrado telas de algodón, no porque no estuvieran disponibles en el mercado, o porque los individuos no tuvieran el dinero suficiente para adquirirlas, sino por una elección deliberada de no utilizarlas, al menos como parte del ritual funerario de vestir al muerto.

El asunto de la elección de la indumentaria funeraria implica, entonces, la toma de decisiones mediadas por factores culturales mucho más amplios a los simples juicios de gusto personal; esto se observa en la escasa diversidad de los tipos de tejido y objetos encontrados en las excavaciones y que se repiten más o menos con cierta regularidad en los entierros; un ejemplo de esto son las suelas de zapato, que pese a la cantidad de fragmentos encontrados, solamente parecen corresponder a tres tipologías.

Desde luego, puede ser que localmente no existiera mucha variedad en la fabricación del calzado, pero algo similar se observa con los hilos de seda y los terciopelos importados que se parecen mucho entre sí, frente a la amplia gama de ofertas que existían en el mercado europeoamericano, tal como se observa en los muestrarios de telas y encajes del siglo XVIIl del Archivo de Indias de Sevilla.

Este hecho implica, entonces, que los familiares seguían pautas de selección de la ropa y el atuendo con el que iban a vestir a sus muertos, quizás bajo la lógica de mostrarlos y de recordarlos "con sus mejores galas", como parte de una práctica asociada a la idea del tránsito hacia la otra vida, pero también, como un intento de mantener el estatus y la diferencia que seguramente construyeron a lo largo de su vida a través de su propio vestuario, pues no se descarta que para este momento, la costumbre de enterramiento implicara, por ejemplo, vestir al muerto con su ropa favorita, tal como ocurre en la actualidad.

Más allá de las razones que median este tipo de decisiones, lo cierto es que las mantas de lana, los hilos de seda y oro, las telas de satín y terciopelo y las suelas de cuero en los zapatos, parecen ser un denominador común que se mantuvo por más de doscientos años, si se tienen en cuenta las fechas registradas para los entierros.

Lo mismo se puede decir del tipo de ornamentos y objetos personales que casi en la totalidad de los casos correspondían a artículos religiosos como escapularios, crucifijos y rosarios, que hacen pensar en la existencia de un mercado floreciente para este tipo de bienes asociados con la lglesia Católica.

Pero estas combinaciones y alternativas en el uso de diferentes prendas y ornamentos, también pueden estar apuntando a que las personas enterradas no eran precisamente españoles sino más bien criollos, quienes eran, de acuerdo con la indagación de los testamentos, las personas que más poder adquisitivo tenían (Therrien et al., 2003, p. 55).

Esto es solo una hipótesis pues todavía es mucho lo que falta, desde el punto de vista de 
la investigación, para entender realmente cómo vivía la gente durante el período colonial, y sobre todo cómo se influyeron mutuamente los diferentes grupos sociales; es el caso de algunos elementos indígenas que fueron adoptados por los europeos y sus descendientes, e igualmente, elementos europeos que fueron integrados a las costumbres de los indígenas, en un juego de relaciones que no parece ser tan distante a lo que ocurre hoy: ciertos objetos considerados de élite no lo son en realidad, tanto más si se tienen en cuenta las diferentes versiones y reinterpretaciones que las personas siguen teniendo al vestirse, empleando, desde luego, la creatividad personal y no solo un uniforme rígido que parece salido de una lámina de revista, aunque la uniformidad aparente que genera la moda parece ser una tendencia que ya en la colonia existía; este trabajo mira las similitudes pero invita a pensar la diversidad.

\section{Bibliografía}

Boucher, F. y Deslandres, Y. (1987). 20,000 years of fashion. The History of costume and personal adornment. Nueva York: Harry N. Abrams Inc.

Cochran, M. D. y Beaudry, M. C. (2006). Material Culture Studies and Historical Archaeology. In Hicks, D. y Beaudry, M. C. (ed.). The Cambridge Companion to Historial Archaeology. Reino Unido: Cambridge University Press.

Contreras, D. y Durand, S. (2009). Santos Inocentes - Tránsito de imágenes. Una mirada histórica, una mirada estética sobre el deterioro. Catálogo de la exposición. Lima: Forma e lmagen.

Di Paolo, D. y Loren, M. (2006). Becoming American: Small Things Remembered. In Hall, M. y
Silliman, S. W. (ed.). Historical Archaeology. Reino Unido: Blackwell Publishing.

Joaquin, E. A. (2008). Entierros coloniales en el antiguo pueblo de San Pedro de Sacatepequez, del corregimiento del Valle de Guatemala. Diálogos. Revista electrónica de Historia. Número especial.

Martín, J. G. y Díaz, C. (2000). Enterramientos coloniales en la catedral de Panamá La Vieja: un ejercicio de reafirmación de las creencias religiosas. Trace, 38, 80-87.

Patiño, V. M. (1992). Historia de la cultura material en la América Equinoccial. Bogotá: Instituto Caro y Cuervo.

Rivera, J. y Therrien, M. (2004). Informe final estudio arqueológico en el templo de La Candelaria de Bogotá. Bogotá: Fundación Erigaie, Grupo de investigación Herencia Cultural (sp).

Sánchez, J. C. (2008). Del catafalco al ataúd y la urna. Cambios significativos en las prácticas funerarias, Bogotá 1910-2007. Bogotá: Facultad de Ciencias Sociales, Centro de Estudios Socioculturales e Internacionales (CESO), Departamento de Antropología, Universidad de los Andes.

Staniland, K. (2000). Bordadores. Madrid: Akal.

Symonds, M.y Preece, L. (1928). Needlework Through the Ages. Londres: Hodder y Stoughton.

Therrien, M, Lobo, J. y Gaitán, F. (2003). Cultura material y ciudad: civilidad y policía en la Santafé colonial, siglos XVI-XVII. Informe de investigación. Bogotá: Fundación de Investigaciones Arqueológicas Nacionales (FIAN), Banco de la República.

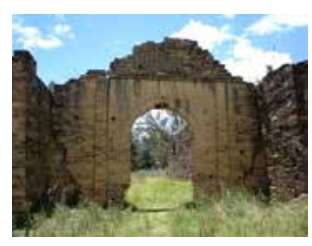

